\title{
Produção científica sobre biodigestores como ações práticas de Educação Ambiental
}

Scientific production on biodigesters as practical actions of Environmental Education

Producción científica sobre biodigestores como acciones prácticas de Educación Ambiental

Thays Oliveira Duarte Graduada em Química, IFMT Campus Confresa, Brasil. thaysoliveiracontinental@gmail.com

Mônica Strege Médici Professora de Biologia, Seduc/MT, Brasil. stregemonica@hotmail.com

Marcelo Franco Leão Professor Doutor, IFMT, Brasil. marccelo.leao@cfs.ifmt.edu.br 


\title{
Revista Científica ANAP Brasil
}

\author{
ISSN 1984-3240 - Volume 13, número 29, 2020
}

\section{RESUMO}

No intuito de minimizar os problemas ambientais, a comunidade científica busca soluções práticas de enfrentamento. Dentre tantas alternativas elaboradas, o biodigestor é uma tecnologia relativamente simples, mas que envolve recursos naturais importantes, além de apresentar resultados compensadores. O objetivo deste estudo investigar a produção científica em periódicos nacionais, dos últimos oito anos, com temas relacionados a biodigestores enquanto ações práticas para promover a Educação Ambiental. Essa pesquisa caracteriza-se como um levantamento bibliográfico, do tipo estado do conhecimento, que investigou a produção científica dos periódicos nacionais, via periódicos CAPES, que foram publicadas entre os anos de 2010 a 2017. A busca se deu por meio da utilização dos descritores biodigestores e Educação Ambiental, prosseguido de leitura flutuante dos títulos, resumos e palavraschave, seleção dos textos relacionados para leitura na íntegra e análise. Foram identificados 7 textos, cuja análise permitiu observar os seguintes critérios: objetivo do estudo, temas abordados, metodologia utilizada, resultados obtidos, considerações chegadas pelos autores e observações realizadas pelos autores pesquisadores. Logo, o presente estudo permitiu verificar nessas pesquisas algumas ações práticas de Educação Ambiental envolvendo os biodigestores.

PALAVRAS-CHAVE: Ações sustentáveis. Recursos naturais. Tratamento de resíduos.

\begin{abstract}
In order to minimize environmental problems, the scientific community seeks practical solutions for coping. Among so many alternatives developed, the biodigester is a relatively simple technology, but it involves important natural resources, in addition to presenting compensating results. The aim of this study is to investigate the scientific production in national journals of the last eight years with themes related to biodigesters as practical actions to promote Environmental Education. This research is characterized as a bibliographic survey, of the state of knowledge type, which investigated the scientific production of national journals, via CAPES journals, which were published between the years 2010 to 2017. The search was made using the descriptors biodigesters and Environmental Education, followed by a floating reading of titles, abstracts and keywords, selection of related texts for full reading and analysis. Seven texts were identified, whose analysis allowed observing the following criteria: objective of the study, topics covered, methodology used, results obtained, considerations received by the authors and observations made by the authors. Therefore, the present study allowed to verify in these researches some practical actions of Environmental Education involving biodigesters.
\end{abstract}

KEYWORDS: Sustainable actions. Natural resources. Waste treatment.

\section{RESUMEN}

Para minimizar los problemas ambientales, la comunidad científica busca soluciones prácticas para hacer frente. Entre tantas alternativas desarrolladas, el biodigestor es una tecnología relativamente simple, pero involucra importantes recursos naturales, además de presentar resultados compensatorios. El objetivo de este estudio es investigar la producción científica en revistas nacionales de los últimos ocho años con temas relacionados con los biodigestores como acciones prácticas para promover la Educación Ambiental. Esta investigación se caracteriza como una encuesta bibliográfica, del tipo de estado del conocimiento, que investigó la producción científica de revistas nacionales, a través de revistas CAPES, que se publicaron entre los años 2010 a 2017. La búsqueda se realizó utilizando los descriptores biodigestores y Educación Ambiental, seguido de una lectura flotante de títulos, resúmenes y palabras clave, selección de textos relacionados para lectura y análisis completos. Se identificaron siete textos, cuyo análisis permitió observar los siguientes criterios: objetivo del estudio, temas cubiertos, metodología utilizada, resultados obtenidos, consideraciones recibidas por los autores y observaciones realizadas por los autores. Por lo tanto, el presente estudio permitió verificar en estas investigaciones algunas acciones prácticas de Educación Ambiental con biodigestores.

PALABRAS CLAVE: Acciones sostenibles. Recursos naturales. Tratamiento de residuos. 


\title{
Revista Científica ANAP Brasil
}

\author{
ISSN 1984-3240 - Volume 13, número 29, 2020
}

\section{INTRODUÇÃO}

Muitas pessoas consideram que um lixo a mais ou outro a menos já não faz tanta diferença na preservação do meio ambiente, do qual o ser humano retira seu sustento e condições de sobrevivência. Esse quadro só piora, pois sabe-se que vivenciamos crises ambientais, devido à exploração de recursos naturais de forma desenfreada somada com os diversos tipos de poluição. Porém, em contraponto a essa situação, estão aumentando os estudos voltados ao desenvolvimento de ações que visam minimizar os graves problemas que o planeta Terra enfrenta.

A busca por tecnologias que amenizem a poluição ambiental tem sido fundamental, principalmente na área produtiva, com objetivo de reduzir estes impactos. As empresas começam a rever suas estratégias, suas estruturas e suas responsabilidades junto à sociedade, para que assim possam ajudar a minimizar a degradação do meio ambiente.

Segundo Bouallagui et al. (2009), essa responsabilidade passa a ser importante e fortemente envolvida com o meio ambiente, o qual está diretamente ligado à sociedade. As empresas passam a visar à responsabilidade social e não somente os lucros, ganhando o reconhecimento da sociedade que valoriza e prefere estas empresas, já que elas conciliam a obtenção de lucros com os trabalhos sociais.

Brilhante e Caldas (1999, p. 33) enfatizam que as atividades humanas têm produzido, ao longo das últimas décadas, uma elevação da concentração de certos gases que dificultam a dissipação refletida pela Terra. Esses gases, como o gás carbônico $\left(\mathrm{CO}_{2}\right)$ e o metano $\left(\mathrm{CH}_{4}\right)$, os clorofluorcarbonos (CFCs), o óxido nitroso e o ozônio atmosférico podem perturbar o equilíbrio o energético entre a Terra e a atmosfera, e, por consequência, o nosso sistema climático.

Cabe ressaltar que um problema sempre atrai uma solução. Nos bancos de pesquisas, juntamente planejadores e executores, podem ser encontrados inúmeras soluções totais ou que, ao menos, amenizem a poluição. Alguns exemplos, como uso da energia elétrica como combustível automobilístico, já cooperam para diminuição de emissão de dióxido de gás na atmosfera, visto que teve notoriamente aumento relacionado ao consumo automobilístico.

Uma maneira de minimizar os impactos da poluição no meio ambiente é utilização do biodigestor. Assim, o problema que norteou este artigo foi: $O$ que revelam os estudos realizados no país, que foram publicados nos últimos oito anos em periódicos nacionais, sobre o uso de biodigestores como prática ambiental?

Em questões racionais, vivemos a realidade onde a natureza é o sustento da humanidade, e ela oferece todos os recursos que necessitamos. É importante reutilizar os recursos. O biodigestor é uma tecnologia simples, mas com grandes valores e resultados compensadores.

Relatar sobre o que pode ser encontrado sobre essa temática, em um dos mais relevantes bancos de pesquisas disponíveis, é um dos desafios encontrados na escolha desse tema. Porém, a curiosidade e a busca por resultados a respeito desta tecnologia, foi a maior influência na elaboração deste texto.

O objetivo deste estudo é investigar a produção científica em periódicos nacionais, dos últimos oito anos, com temas relacionados a biodigestores enquanto ações práticas para promover a Educação Ambiental. 


\section{Revista Científica ANAP Brasil}

ISSN 1984-3240 - Volume 13, número 29, 2020

Nesse texto, inicialmente apresenta-se a discussão sobre o tratamento de resíduos. A segunda seção abordou o conceito, os tipos e a classificação dos biodigestores. A terceira seção descreve os procedimentos que permitiram realizar o estudo, ou seja, aborda a exposição do percurso de pesquisa realizado. A quarta seção apresenta a produção científica encontrada e a relação do tema biodigestores com a Educação Ambiental. Por fim, são apresentadas algumas considerações sobre a realização deste estudo, seguido da listagem de referências utilizadas.

\section{TRATAMENTO DE RESÍDUOS}

Nas últimas décadas, mais do que debater sobre as causas da poluição e seus impactos, nota-se um esforço de estudiosos em minimizar tais impactos e a preocupação a longo prazo no que se refere ao gerenciamento dos resíduos. De acordo com Reichert e Mendes (2014, p. 302), "Para a definição dos sistemas sustentáveis de manejo de resíduos, a montagem de cenários com diferentes opções de coleta, de tratamento e de disposição final tem sido utilizada".

Os autores denominam como cenários de gerenciamento de resíduos as diversas alternativas para manejo dos resíduos, onde devem ser considerados "as etapas de coleta, transporte, triagem centralizada, reciclagem de materiais, tratamento biológico, tratamento térmico e aterro sanitário" (REICHERT; MENDES, 2014, p. 302). A combinação de técnicas diferentes pode gerar um sistema ambientalmente mais efetivo em relação a suas emissões, sejam gasosas, líquidas e residuais, além se ser necessário se analisar aspectos econômicos e sociais.

Tendo em vista a necessidade de reduzir riscos e facilitar a sua disposição final, os resíduos podem ser submetidos a processos de tratamento que alterem seu caráter ou sua composição, considerando a manipulação e custo. Segundo Oliveira e Oliveira (2014), esses procedimentos podem ocorrer no próprio local de geração ou externamente, sendo aplicáveis tanto a resíduos sólidos, quanto aos resíduos químicos e aos infectantes.

Há uma maior atenção a determinados processos de tratamento ou disposição final para resíduos sólidos urbanos, uma vez que estão mais adequados à legislação, ao domínio do manejo ou pela sua maior aceitação. No entanto, diversos processos formam um grande conjunto de tecnologias, das quais podem ser destacados: "aterro sanitário, biodigestor, compostagem, incineração por combustão, gaseificação e pirólise" (OLIVEIRA; OLIVEIRA, 2014, p. 299).

No Brasil, em de 2 de agosto de 2010, foi promulgada e sancionada a Lei № 12.305, também chamada de Lei da Política Nacional de Resíduos Sólidos (PNRS), que introduz conceitos que devem estruturar a política de resíduos sólidos de cada um dos entes da Federação, inclusive da própria União, sendo o marco regulatório na temática que preconiza, entre outras coisas que:

Na gestão e gerenciamento de resíduos sólidos, deve ser observada a seguinte ordem de prioridade: não geração, redução, reutilização, reciclagem, tratamento dos resíduos sólidos e disposição final ambientalmente adequada dos rejeitos (BRASIL, 2010, Art. 3).

A PNRS dispõe sobre princípios, objetivos e instrumentos, bem como sobre as diretrizes relativas à gestão integrada e ao gerenciamento de resíduos sólidos, incluídos os perigosos, às 


\title{
Revista Científica ANAP Brasil
}

\author{
ISSN 1984-3240 - Volume 13, número 29, 2020
}

responsabilidades dos geradores e do poder público e aos instrumentos econômicos aplicáveis (BRASIL, 2010).

Como mencionado anteriormente, existem atualmente diferentes processos, técnicas e métodos que podem, e deveriam ser utilizados para o processamento dos diferentes tipos de resíduos. Essas soluções oferecem diferentes alternativas desenvolvidas e aperfeiçoadas nas últimas décadas de forma a propiciar o tratamento mais adequado e vantajoso para cada resíduo de acordo com a realidade de cada organização, bem como atender à legislação vigente. Outra alternativa que se apresenta, dentre tantas possíveis, é a destinação dos resíduos para incineração que, de acordo com Boff (2013), consiste em um processo de redução de peso e volume das características de periculosidade dos resíduos, com a consequente eliminação da matéria orgânica e características de patogenicidade, por meio da combustão controlada.

Dessa forma, a partir da definição dos processos acima mencionados, percebe-se que nem todo processo visa a aproveitar a geração de energia e/ou de matéria orgânica como subprodutos finais dos resíduos sólidos tratados.

No processo de compostagem, há uma decomposição aeróbia da matéria orgânica produzindo um subproduto utilizável como adubo orgânico. A compostagem pode aproveitar matérias primas de origem animal ou vegetal, sendo que esses materiais podem ser enriquecidos [...] com minerais ou agentes capazes de melhorar suas características físicas, químicas ou biológicas e isento de substâncias proibidas pela regulamentação de orgânicos (BRASIL, 2012).

De acordo com Pereira et al. (2015), o referido mecanismo é composto por uma câmara fechada, na qual se insere o material orgânico misturado com água, ocorrendo a decomposição anaeróbia e geração de biogás.

Diferentemente das técnicas e métodos mencionados acima, o biodigestor apresenta maior viabilidade de implementação no que tange ao seu aspecto econômico, considerando, sobretudo, que os produtos gerados podem ser consumidos e/ou comercializados, entre eles os créditos de carbono, o biogás (que pode ser transformado em energia elétrica) e o biofertilizante (PEREIRA et al., 2015). Esse assunto é apresentado e discutido com mais profundidade na próxima seção.

\section{REFLEXÕES TEÓRICAS SOBRE BIODIGESTORES}

De acordo com Rocha (2014), o biodigestor é definido simplesmente por uma câmara sem oxigênio e a fermentação do principal material que é dejetos animais (biomassa). É possível, assim, definir biodigestor como um aparelho destinado a conter a biomassa e seu produto: 0 biogás.

Conforme a definição de Rocha (2014, p. 11): “O biodigestor, como toda grande ideia, é genial por sua simplicidade". Nesse processo, a fermentação da biomassa resulta em formação do gás metano, fonte de combustível puro ou transformado em energias. Por sua vez, o gás metano (CH4) é um poluidor natural, assim como o óxido nitroso (N2O) e ozônio (O3). Ele é encontrado em pântanos (e dá origem ao cheiro característico dessa região), decomposições de matérias orgânicas, ou fermentação anaeróbica dessas matérias. A maior quantidade é encontrada em leitos marinhos, porém o aumento significativo na agropecuária assustou, e têm colaborado para mais estudos e implantações de biodigestores caseiros ou em grandes escalas. 


\title{
Revista Científica ANAP Brasil
}

\author{
ISSN 1984-3240 - Volume 13, número 29, 2020
}

Em seus estudos, Barrera (2003) destaca também que o biodigestor em material não é o principal produtor de sua maior fonte de resultado, biogás. Ele somente propícia a degradação do material orgânico à um grupo de bactérias denominadas metano gênico. Gaspar (2003) complementa essa ideia de somente um grupo de bactérias produzir o gás $\mathrm{CH}_{4}$, destacando que a fermentação anaeróbica tem a participação de incontáveis espécies de bactérias, que de alguma forma coopera para a produção dele. Essa degradação anaeróbica resulta em fermentação do material orgânico e consequentemente à produção de biogás.

Ainda segundo Gaspar (2003), existem vários tipos de biodigestores, mas, em geral todos são compostos, basicamente, de duas partes: um recipiente (tanque) para abrigar e permitir a digestão da biomassa, e o gasômetro (campânula), para armazenar o biogás.

Os biodigestores podem ser encontrados em diversos modelos (canadense, indiano, chinês, entre outros), cada qual com suas vantagens e desvantagens e características próprias de operação. Entretanto, existem dois tipos básicos de biodigestores classificados de acordo com a frequência de operação.

A água tem uma importância enorme na biodigestão, quando junto com o material orgânico, pois propícia a função enzimática e posteriormente favorece a ação os micro-organismos na decomposição da matéria (DIAS, 2009).

Existem os tratamentos com pouca água também. Estes permitem maior volume de material (que geralmente são lixos industriais e caseiros), porém são menos sensíveis a impurezas e tem tempo de decomposição mais lenta em comparação ao ambiente mais úmido.

Uma curiosidade é a inserção de inóculos na decomposição dos substratos. Inóculos nessa citação, são matérias que já passaram pelo biodigestor, e contém os microrganismos para acelerar o processo da biometanização, o que é notoriamente eficaz em processos com menos umidade, visto que que acelera o processo (BOUALLAGUI, et al., 2004).

O processo que o biodigestor realiza, é dividido em várias etapas. Contudo, segundo Vandevivere et al. (2002), elas podem ser classificadas em superficialidade por duas: a primeira é a hidrolise da acidificação e liquefação. A segunda é a transformação do hidrogênio, 26 acetato e óxido de carbono, em metano.

O nome estágio é comum quando se estuda vários artigos sobre biodigestores, ou numa leitura sobre o assunto. Estágio é simplesmente a classificação das etapas citada acima. Por exemplo, os biodigestores que passam essas etapas de uma só vez, é chamada de sistema de um só estágio. As que dividem em duas etapas, sistema de dois estágios e da terceira em diante, sistema de estágios.

O biodigestor anaeróbico possui muitos benefícios em várias áreas, como no ensino, na preservação, conservação, produção, pesquisa entre outros. Mas uma das que se destaca é o benefício financeiro, pois ele entrega o biogás que pode ser aproveitado como combustível de abastecimento ou transformado em energia elétrica (SILVA et al., 2015).

Assim, é possível compreender que os biodigestores são capazes de evitar poluição de dejetos e lixos, e por isso são considerados e utilizados como meio sustentável. Que o biodigestor só tem a oferecer coisas boas, já foi possível compreender. Na Tabela 1 possibilita conhecer os diferentes biodigestores existentes, suas diferenças e similaridades. 
Revista Científica ANAP Brasil

ISSN 1984-3240 - Volume 13, número 29, 2020

Tabela 1: Modelos de Biodigestores

\begin{tabular}{|c|c|c|}
\hline Modelo & Fluxo de carregamento de biomassa & Principais elementos do biodigestor \\
\hline Chinês & continuo & $\begin{array}{l}\text { Reservatório de biomassa } \\
\text { Reservatório de biofertilizante } \\
\text { Cúpula de gás } \\
\text { Tanque de fermentação com divisão }\end{array}$ \\
\hline Indiano & continuo & $\begin{array}{l}\text { Reservatório de biomassa } \\
\text { Reservatório de biofertilizante } \\
\text { Cúpula de gás } \\
\text { Tanque de fermentação sem divisäo }\end{array}$ \\
\hline Canadense & continuo & $\begin{array}{l}\text { Lagoa de biomassa } \\
\text { Lona para armazenamento de gás } \\
\text { Reservatório de biofertilizante }\end{array}$ \\
\hline Bioköhler & contínuo & $\begin{array}{l}\text { Reservatório de biomassa } \\
\text { Reservatório de biofertilizante } \\
\text { Fermentador com funil de separação } \\
\text { Balão de gás }\end{array}$ \\
\hline Batelada & não-continuo & $\begin{array}{l}\text { Fermentador } \\
\text { Reservatório de biofertilizante }\end{array}$ \\
\hline
\end{tabular}

Fonte: Duarte Neto et al. (2010).

O diferencial entre os modelos da tabela, é o denominado batelada, isso porquê o seu abastecimento é de forma descontínua, ou seja, entre certos intervalos de tempos. Isso acontece uma vez a cada ciclo e com um número maior de material orgânico, ficando em contenção por 45 a 60 dias.

A matéria orgânica só é retirada quando ocorre a total decomposição, produzindo assim menos biogás, mas contrapartida, mais fertilizante. Parte desse material decomposto é deixado na câmara anaeróbica para possibilitar o próximo processo de abastecimento (inóculos), essa porcentagem de fertilizante, é em média $20 \%$. Porém os modelos mais usados no Brasil, são os de abastecimento contínuos, que contem movimentação por meio de cargas hidráulicas. São escolhidos pelos fáceis manuseios, baixo custo e alto rendimento (DUARTE NETO et al., 2010).

\section{PROCEDIMENTOS METODOLÓGICOS}

O presente estudo caracteriza-se como um levantamento bibliográfico, do tipo estado do conhecimento, que investigou a produção científica dos periódicos nacionais de 2010 a 2017. Considera-se, portanto, que o processo de pesquisa se constitui em uma atividade científica básica que, por meio da indagação e (re) construção da realidade, alimenta a atividade de ensino e a atualiza frente à realidade. Assim como vincula pensamento e ação já que "nada pode ser intelectualmente um problema se não tiver sido, em primeiro lugar, um problema da vida prática" (MINAYO, 2001, p. 17).

A pesquisa foi realizada nos Periódicos $C A P E S^{1}$, por meio de seus bancos de dados nos primeiros meses do ano de 2019. Cabe ressaltar que Periódicos CAPES é uma plataforma onde possibilita o acesso sem custo a patentes de nível nacional e internacional, possui 45 mil títulos com texto completo, 130 bases referenciais, 12 bases dedicadas exclusivamente a patentes (CAPES, missão e objetivo). A plataforma é usada para o auxílio à acadêmicos, professores e pesquisadores. Ela

\footnotetext{
${ }^{1}$ Plataforma disponível em: https://www.periodicos.capes.gov.br/
} 


\title{
Revista Científica ANAP Brasil
}

\author{
ISSN 1984-3240 - Volume 13, número 29, 2020
}

reúne pesquisas nacionais e internacionais, possuem filtros de temas, idiomas, palavras-chaves, nacionalidade e ainda oferecem a sua plataforma, gratuitamente.

Primeiramente foi acessado o site do capes para fazer a pesquisa dos artigos Biodigetores; Educação Ambiental. No assunto Biodigestor foram encontrados 323 estudos, dos anos de 1982 a 2019. Logo em seguida, foram acrescentadas as palavras Educação Ambiental, e foram encontrados somente 08 resultados, porém relacionados a Educação Ambiental no ensino, foram selecionados apenas 7 deles para a análise, o que é esclarecido em seguida.

A análise do conteúdo desses artigos incluiu três etapas: (I) leitura do título, resumo e palavraschave; (II) seleção e download; (III) leitura na íntegra e análise. Durante a leitura dos resumos, procurou-se notar a presença de relações entre a utilização dos biodigestores com as práticas de Educação Ambiental.

Posteriormente, foi realizada uma análise de cada texto selecionado. Foi possível notar que em um pequeno resultado de quantidades de artigos, é capaz de suprir as necessidades do pesquisador da plataforma na mesma linha de campo deste. Nessa pesquisa, foram encontrados artigos técnicos, de construção, cálculos prévios, ensinamentos de montagens de modelos, teoria explicativa, empregabilidade do biodigestor em escolas e comunidades, entre uma vasta gama que tem possibilidade de ser encontrada.

O último artigo citado acima, foi descartado nesta primeira fase, pois não apresenta o conteúdo relacionado ao biodigestor, mas sim uma pesquisa interessante sobre o cultivo de alfaces com materiais orgânicos como esterco, simplesmente o deixando fermentar por alguns dias. Porém não tem o uso do biodigestor anaeróbico.

Ao todo, foram considerados 07 artigos encontrados, e realizado o fichamento de cada um com liberdade de exposição de opinião dos autores/investigadores. Foram utilizados os seguintes critérios para analisar os dados: objetivo do estudo, temas abordados, metodologia utilizada, resultados obtidos, considerações chegadas pelos autores e observações realizadas pelos autores pesquisadores.

\section{RESULTADOS E DISCUSSÕES}

Os resultados encontrados sobre a produção científica publicada nos anos 2010 a 2017, no periódico nacional CAPES sobre biodigestores e Educação Ambiental, são apresentados no Quadro 1. Como características dessa produção, foram observados os objetivos principais dos estudos, as temáticas abordadas, as metodologias empregadas e os principais resultados obtidos, seguido de uma reflexão de como os biodigestores podem ser explorados como práticas de Educação Ambiental. 
Revista Científica ANAP Brasil

ISSN 1984-3240 - Volume 13, número 29, 2020

Quadro 1: Características da produção científica encontrada

\begin{tabular}{|c|c|c|c|}
\hline Artigo & Objetivo & Temas abordados & Metodologia \\
\hline KRETZER et al., (2017) & $\begin{array}{l}\text { Importância da gestão } \\
\text { ambiental }\end{array}$ & $\begin{array}{l}\text { Sustentabilidade, } \\
\text { consciência ecológica e Eco } \\
\text { alfabetização }\end{array}$ & $\begin{array}{l}\text { Construção de um } \\
\text { biodigestor e inserção dele } \\
\text { no ensino }\end{array}$ \\
\hline RIBEIRO (2011) & $\begin{array}{l}\text { Modelo de cálculo } \\
\text { dimensional }\end{array}$ & $\begin{array}{l}\text { Dimensões, excrementos } \\
\text { animais. }\end{array}$ & $\begin{array}{l}\text { Cálculos de um biodigestor } \\
\text { em proporção ao material } \\
\text { orgânico }\end{array}$ \\
\hline VALASKI, (2010) & Qualidade ambiental & $\begin{array}{l}\text { Planejamento da Paisagem, } \\
\text { sustentabilidade, pesquisa }\end{array}$ & $\begin{array}{l}\text { Pesquisas sobre } \\
\text { sustentabilidade em dois } \\
\text { condomínios }\end{array}$ \\
\hline SILVA et al., (2015) & $\begin{array}{l}\text { Ambiente de } \\
\text { aprendizado concreto }\end{array}$ & $\begin{array}{l}\text { Biodigestor, biogás, } \\
\text { biofertilizante, dejetos }\end{array}$ & $\begin{array}{l}\text { Construção de um } \\
\text { biodigestor, modelo indiano }\end{array}$ \\
\hline $\begin{array}{l}\text { TEPERINO et al., } \\
(2017)\end{array}$ & $\begin{array}{l}\text { Testes de produção de } \\
\text { biogás com resíduos da } \\
\text { cafeicultura e } \\
\text { bovinocultura }\end{array}$ & $\begin{array}{l}\text { Codigestão anaeróbica, } \\
\text { energia renovável, } \\
\text { sustentabilidade }\end{array}$ & $\begin{array}{l}\text { Construção de biodigestor } \\
\text { didático }\end{array}$ \\
\hline PEREIRA et al., (2015) & $\begin{array}{l}\text { Separação do dióxido } \\
\text { de carbono do metano }\end{array}$ & $\begin{array}{l}\text { Dióxido de carbono, } \\
\text { hidróxido de bário, biogás, } \\
\text { biomassa }\end{array}$ & $\begin{array}{l}\text { Reação do dióxido de } \\
\text { carbono com hidróxido de } \\
\text { bário }\end{array}$ \\
\hline $\begin{array}{l}\text { VENTURA; } \\
\text { FERNANDEZ; } \\
\text { ANDRADE (2012) }\end{array}$ & Tecnologias sociais & $\begin{array}{l}\text { Tecnologias sociais, } \\
\text { desenvolvimento humano, } \\
\text { mudanças climáticas, } \\
\text { semiárido baiano. }\end{array}$ & $\begin{array}{l}\text { Pesquisas de tecnologias } \\
\text { capazes de mudar o cenário } \\
\text { de seca da região nordeste } \\
\text { brasileira. }\end{array}$ \\
\hline
\end{tabular}

Fonte: Elaborado pela autora baseado nos dados coletados na pesquisa (2019).

No estudo de Kretzer et al. (2015), a Educação Ambiental foi relacionada a gestão de resíduos e ao uso de biodigestores em escola pública. Nessa investigação, o objetivo foi demonstrar por meio de uma gestão participativa com crianças de uma escola de educação básica Municipal de Florianópolis, a importância da Educação Ambiental, que usou o biodigestor como instrumento de ensino.

Kretzer et al. (2015) citam o uso de combustíveis não renováveis e sobre a crise do petróleo que ocorreu na década de 70 , foi o incentivo para alavancar pesquisas e desenvolvimentos sobre energias renováveis. O Brasil optou por fontes renováveis e substitutas dos combustíveis fósseis não renováveis como o xisto, álcool e metanol. Relembrando que este último supracitado, é o principal produto do biodigestor.

Associa a produção do biogás, não somente pelas bactérias metanogênicas, mas também várias espécies de bactérias, que por alguma forma cooperam para a formação do metano (COELHO et al., 2006). O metano não é somente um gás totalmente puro, mas cerca de 60 a $80 \%$ do biogás o possui.

A metodologia utilizada por Kretzer et al. (2015), foi participativa, onde envolveram estudantes, colaboradores da escola, e indiretamente os pais dos estudantes. Se dedicou a expor os temas: fontes de energias renováveis e não renováveis; importância da seletividade do lixo; os objetivos e benefícios de se tratar o composto orgânico; a problemática causada pelos dejetos \manejos incorretos desses compostos e suas consequências ao ambiente; e as alternativas para o tratamento dos mesmos, com opção da construção de um biodigestor, utilizando resíduos já tratados para promover agricultura urbana na própria instituição de ensino. Os estudantes participaram na construção, manutenção e manuseio do biodigestor (KRETZER, et al., 2015).

Foi usado além de somente um método para avaliação e assim concluir as análises, entre elas: fichas de questionários, participação das aulas expositivas, maquetes, vídeos, cultivo de hortas, 


\title{
Revista Científica ANAP Brasil
}

\author{
ISSN 1984-3240 - Volume 13, número 29, 2020
}

folhetos e biodigestor em miniatura. Cabe ressaltar que a partir desse trabalho desenvolvido por Kretzer et al. (2015), surgiu um grupo de educadores, que usaram os conhecimentos adquiridos para desenvolver mais dinâmicas que retratem a realidade socioambiental. Segundo nossa avaliação, esse foi um resultado considerável do artigo, pois informação é poder, e qualquer atitude que colabore na mudança de nossa realidade é válida.

O estudo desenvolvido por Silva et al. (2015), buscou determinar as dimensões de um biodigestor em função da proporção gás/fase líquida. $O$ foco do estudo foi chegar a um modelo de cálculos utilizando Excel e AutoCAD, para saber exatamente as proporções que precisará ter o biodigestor em relação ao material orgânico e água. Nas palavras do autor: "Calcular as dimensões de um biodigestor tubular em função da proporção gás/fase líquida desejada" (SILVA et al. 2015, p. 35).

Esse estudo foi basicamente o desenvolvimento do estudo matemático em análises computacionais, para chegar ao modelo. No artigo, o autor supracitado apresenta citações direta e indiretas que defendam sua ideia de pesquisa, e também os métodos passo a passo de todo o cálculo, até a conclusão. Isso possibilitou mostrar que a aplicação do modelo para saber suas exatas proporções em relação ao material orgânico úmido.

Valaski (2010) utilizou um método de avaliação da qualidade ambiental em condomínios residenciais horizontais, o qual envolveu inicialmente discussões teóricas e chegou à avaliação de dois condomínios no bairro Santa Felicidade, município de Curitiba/PR, envolvendo o uso de biodigestores. A pesquisa foi embasada em publicações referente ao tipo de ocupação de solo urbano, que vêm se propagandeando cada vez mais em território brasileiro: condomínios residenciais horizontais. Destaca-se o foco desses trabalhos pesquisados, a grande quantidade dos temas: aspectos econômicos, sociais e culturais. Porém, não é comum a temática ambiental, no qual se propõe pesquisas afim de avaliar a qualidade ambiental nesse tipo de habitação.

A expectativa do tipo condomínios horizontais, é de ser consideravelmente mais planejada do que as construções comuns, onde se espera organização maior em todos os temas relacionados à pesquisa do trabalho (VALASKI, 2010). O trabalho teve a linha do planejamento da paisagem, priorizando as questões ecológicas, onde busca absorver o máximo dos que os recursos naturais têm a oferecer, afim de diminuir o consumo de energia.

Ao refletir sobre o estudo de Valaski (2010), é possível afirmar que o mesmo contribui para a Educação Ambiental, pois envolve biodigestor e educação ambiental. Nota-se essa preocupação no início, onde cita: "As possibilidades de um a vida mais segura, em contato com a natureza e em alto estilo, são apelos veiculados pelas construtoras no momento da venda destes empreendimentos" (VALASKI, 2010, p. 43).

Com essa urgência em implantação de qualidade da paisagem, que define o Planejamento da Paisagem. Essa linha contém atributos como cobertura vegetal arbórea, espaços livres de edificações, opções de recreações ao ar livre (quadras esportivas por exemplo), permeabilidade do solo, formas de arruamentos, distância mínima entre as edificações e os atributos objetivos e específicos, no qual o biodigestor faz parte.

A presença de biodigestores nesses casos de alta escala, seria consideravelmente bem aproveitado devido à demanda de material orgânico e também o aproveitamento dos produtos (biogás e biomassa), além de que cumpriria ao que exige o Planejamento da Paisagem, em âmbitos relacionais à preservação da natureza, como citado no objetivo, gerando assim energia 


\title{
Revista Científica ANAP Brasil
}

\author{
ISSN 1984-3240 - Volume 13, número 29, 2020
}

renovável ao condomínio e até estercos (restos de comidas nesse caso) para plantações de hortas locais.

Nos estudos desenvolvidos por Silva et al. (2015), sobre as implicações e possibilidades para o ensino a partir da construção de biodigestor no Instituto Federal do Rio Grande do Norte (IFRN) Campus Apodi. Algumas constatações possibilitadas pelo estudo foram que a atividade favoreceu a concretização de aprendizados (aprender com a "mão na massa"), a integração de várias disciplinas para compreender o processo e a divulgação da tecnologia aos produtores rurais da região.

No estudo desenvolvido por Teperino et al. (2017), foi utilizado um digestor anaeróbio didático para discutir sobre a utilização de combustíveis fósseis atual, e o quanto isso degrada o meio ambiente. A metodologia utilizada foi a construção e testes da produção do biogás utilizando resíduos da bovinocultura e cafeicultura (palhas da pós-colheita). $\mathrm{O}$ trabalho foi executado na região Nordeste Fluminense, mas o interessante é que a realização dos testes de produção de biogás, foram feitos em biodigestores compostos por garrafas PET e PVC, sustentável e de baixo custo: "Buscar soluções tecnológicas sustentáveis é uma necessidade para promover o desenvolvimento socioeconômico da região Noroeste Fluminense" (TEPERINO, et al., 2017).

Como já notado no trecho supracitado, a busca por recursos sustentáveis, é de interesse em nível mundial, mas também pode começar por pequenos feitos. 0 esforço para fazer notório o desenvolvimento ambiental, seria mais eficaz se o interesse de pequenas comunidades reconhecesse o quanto é necessário agir rápido para mudar o cenário que o planeta enfrenta. $\mathrm{Na}$ oportunidade foi montada uma planilha expondo os principais cultivos agrícolas e rebanhos pecuários da região, dentre eles estão o arroz, café, milho, tomate e os rebanhos bovinos, caprinos, ovinos e suínos, juntamente com suas produções e números de cabeças, exibindo assim a propiciação de instalação de um digestor.

Pereira et al. (2015) realizaram uma avaliação de sistema de colunas para remediação de biogás a partir de biomassa não digerida, ou seja, o artigo enfatiza sobre uma problemática do biodigestor na produção do biogás. Nessa situação, o metano que é o principal produto, vem acompanhado de outros gases, como dióxido de carbono (em grandes quantidades e também sulfídrico e hidrogênio (em pequenas quantidades). O Dióxido de Carbono é considerado indesejado na produção de metano, por não ser inflamável, e o objetivo do trabalho consiste em "retirar" esse dióxido de carbono por meio da reação com o Hidróxido de Bário, obtendo assim o Carbonato de Bário. O Carbonato de Bário é tóxico, porem conforme autores do artigo citado, tem utilidades em diferentes industrias.

O artigo supracitado aborda sobre a importância da produção de energia sustentável, o uso do biodigestor como fonte de energia e ainda o propósito de retirar gases prejudiciais nessa reação. Apresenta fases e fatores que influenciam a digestão anaeróbica, cálculos, ambientes, reações e toda a metodologia da problemática e experimentos realizados. Além de gráfico com resultados (inclusive satisfatórios). 0 experimento foi realizado com duração de 30 dias com 100 g de arroz cozido e $200 \mathrm{ml}$ de água potável. A precipitação $\mathrm{CO}_{2}$, resultou $12 \%$ a menos do que apresentado no mesmo processo de digestão anaeróbia sem todo esse processo (PEREIRA et al., 2015). Ressaltando essa porcentagem em aumento de produção do $\mathrm{CH}_{4}$. Resumidamente, é a reciclagem do reciclado. 


\title{
Revista Científica ANAP Brasil
}

\author{
ISSN 1984-3240 - Volume 13, número 29, 2020
}

No estudo de Ventura, Fernandez e Andrade (2012), são abordadas as tecnologias sociais, que podem contribuir para a amenização do efeito estufa, porém, o foco é na região semiárida do Nordeste brasileira. Relatam que alguns estudos realizados pelo ministério do meio ambiente afirmam que o nordeste brasileiro terá menos chuvas, sem períodos corretos e ainda aumentará as secas. Esse artigo demonstra uma certa preocupação, e apresenta recursos que podem ser explorados para combater essa realidade. É um trabalho completo de pesquisa e cita o biodigestor como uma das tecnologias, explicando ainda suas vantagens e retorno em energia. Por meio da realização desse levantamento, foi possível verificar nos estudos relacionados aos biodigestores ações práticas de Educação Ambiental, tais como: biodigestores rurais, gestão ambiental, educação e biomassa, biodigestor caseiro, eficiência energética de sistema de produção de suínos com tratamento dos resíduos em biodigestor, potencial de redução de emissão de equivalente de carbono de uma unidade suinícola com biodigestor, dimensionamento de biodigestor para geração de energia alternativa, avaliação do ecossistema microbiano de um biodigestor anaeróbio de fluxo ascendente e manta de lodo, operado com vinhaça sob condições termofólicas e tratamento de resíduos sólidos orgânicos em biodigestor anaeróbio.

\section{CONSIDERAÇÕES FINAIS}

O campo de pesquisa sobre biodigestores, observado pela busca no Periódico CAPES, aparentemente apresentou poucos resultados, mesmo envolvendo diversas áreas, seja relacionado a cálculos, avaliação de métodos eficientes, condomínios ou como práticas educativas. Contudo, esse número reduzido de produções já é capaz de nos levar a refletir sobre a importância de desenvolver soluções de enfrentamento aos problemas ambientais. Sabemos que a realidade de nosso planeta está cada vez pior, mas existem muitas alternativas que podem ser assumidas pela sociedade, institutos, produtores ou industrias podem. $\mathrm{O}$ biodigestor se apresenta como uma alternativa viável, cujas finalidades são benéficas.

Todo esforço que vise minimizar os impactos ambientais é bem-vindo. O próprio mercado atual exige mudanças fundamentais no comportamento social para que tenha viabilidade de recursos para sua prática econômica. Surgem novos referenciais na gestão de negócios, uma abordagem fundamentalmente inovadora à maneira de pensar para poder compreender e tratar as novas realidades.

Outra reflexão proporcionada pelo estudo é referente a falta de informação da população ou alternativa correta para o descarte de dejetos. Isso tudo envolve a aptidão dos diferentes tipos de solos e culturas para o recebimento de fertilizantes existentes nos dejetos, bem como o efeito sobre o meio ambiente a curto e a longo prazo e da aplicação desses dejetos, o que têm limitado o uso racional dos mesmos.

A prática de lançar os dejetos de forma indiscriminada na natureza, com riscos de contaminação dos solos, mananciais, rios, efluentes e também o próprio ar, afeta diretamente a saúde das comunidades rurais e urbanas e essa prática constitui-se em uma agressão condenável sob todos os aspectos.

Logo, é imprescindível sensibilizar a sociedade sobre os aspectos poluentes dos dejetos, bem como a implantação de um sistema que combine o uso agronômico dos dejetos, como 


\title{
Revista Científica ANAP Brasil
}

\author{
ISSN 1984-3240 - Volume 13, número 29, 2020
}

fertilizantes, proporcionando maior economia de insumos e sistemas que minimizem os efeitos da poluição. Na perspectiva de qualificar as discussões sobre a temática biodigestores relacionando com Educação Ambiental, espera-se que mais pesquisas sejam realizadas de maneira que sejam ampliadas as possibilidades de enfrentamento aos problemas ambientais.

\section{AGRADECIMENTO}

Ao IFMT pala formação recebida, pelo apoio e viabilidade para que o estudo ocorresse e resultasse na presente publicação.

\section{REFERÊNCIAS BIBLIOGRÁFICAS}

BARRERA, P. Biodigestores: energia, fertilidade e saneamento para zona rural. São Paulo: Ícone, 2003. 106 p

BOUALLAGUI, $\mathrm{H}$. et al. Effect of temperature on the performance of an anaerobic tubular reactor treating fruit and vegetable waste. Process Biochemistry, London, v. 39, n. 12, p. 2143-2148, 2004.

BOFF, L. Sustentabilidade - O que é - O que não é. Petrópolis, Vozes, 2013.

BRASIL. Lei no 12.305, de 02 de agosto de 2010. Política nacional de Resíduos Sólidos. Diário Oficial da União, Brasília, 2010. Disponivel em :<https://fld.com.br/catadores/pdf/politica_residuos_solidos.pdf $>$. Acesso dia 09/04/2019;

BRASIL. Plano Nacional de Resíduos Sólidos. (2012). Disponivel e

<https://periodicos.ufsm.br/index.php/reaufsm/article/view/13026>. Acesso dia 10 /04/2019;

BRILHANTE, Ogenis Magno em CALDAS, Luiz Querino de A. Gestão e avaliação de risco em saúde ambiental. Scielo Books eletronic Library online. FIOCRUZ, 1999 p. 33, Disponível em: https://doi.org/10.7476/9788575412411 Acesso dia 10/04/2019;

DIAS, R. Gestão Ambiental: responsabilidade social e sustentabilidade. São Paulo, Atlas, 2009.

DUARTE NETO, E. D.; et al. Implementação e avaliação de um biodigestor de produção descontínua. Revista e-xacta, Belo Horizonte, v.3, n.2, p.36-46, 2010.

GASPAR, R. M. B. L. Utilização de biodigestores em pequenas e médias propriedades rurais com ênfase na agregação de valor: um estudo de caso na região de Toledo/PR. Dissertação de Mestrado. Florianópolis, 2003.

KRETZER, Stéfano Gomes; et al. Educação ambiental em gestão de resíduos e uso de biodigestor em escola pública de Florianópolis. Extensio (Florianópolis), v. 12, p. 2-15, 2015.

MINAYO, Maria. C. S (Org.). Pesquisa social: teoria, método e criatividade. Petrópolis, RJ: Vozes, 2001.

OLIVEIRA, S. V. W. B.; OLIVEIRA, M. M. B. Tecnologias disponíveis para o tratamento ou a disposição adequada de resíduos sólidos urbanos. In: SAIANI, C. C. S.; DOURADO, J.; TONETO JUNIOR, R. Resíduos sólidos no Brasil: oportunidades e desafios da lei federal no 12.305 (Lei de Resíduos Sólidos). Barueri: Minha Editora, 2014.

ORTOLANI, A. F. et al. Bateria de mini-biodigestores: Estudo, projeto, construção e desempenho. In: CONGRESSO BRASILEIRO DE ENGENHARIA AGRÍCOLA, 15. 1986, São Paulo. Anais... Botucatu: FCA/UNESP, 1986. p. 229-239.

PEREIRA, V.; et al. Avaliação de sistema de colunas para remediação de biogás a partir de biomassa não digerida. Holos (Natal. Online), v. 8, p. 242, 2016.

REICHERT, G. A.; MENDES, C. A. B. Avaliação do ciclo de vida e apoio à decisão em gerenciamento integrado e sustentável de resíduos sólidos urbanos. Eng. Sanit. Ambient. [online]. 2014, vol.19, n.3, p.302. ISSN 14134152. Disponivel em <https://doi.org/10.1590/S1413-41522014019000001145. Acesso dia 20 de março de 2019; 


\title{
Revista Científica ANAP Brasil
}

\author{
ISSN 1984-3240 - Volume 13, número 29, 2020
}

RIBEIRO, D. S. Determinação das dimensões de um biodigestor em função da relação gás/fase líquida. Holos (Natal. Online), v. 1, p. 49-56, 2011.

ROCHA, Camila Marçal. Biodigetor Anaerobico de Residuos Alimentares. Disponivel em < http://www.ufjf.br/engsanitariaeambiental/files/2014/02/TCC-camila-final-pdf.pdf>. Acesso dia 10 de abril de 2019.

SILVA, F. F. M. da; et al. Implicações e possibilidades para o ensino a partir da construção de biodigestor no IFRN Campus Apodi. Holos (Natal. Online), v. 6, p. 315-327, 2015.

TEPERINO, D. P. M.; et al. Desenvolvimento de digestor anaeróbio didático e testes de produção de biogás com resíduos da bovinocultura e cafeicultura. Acta Biomedica Brasiliensia, v. 8, p. 57-70, 2017.

VALASKI, S. Método para avaliação da qualidade ambiental em condomínios residenciais horizontais. Ra'e ga (UFPR), v. 19, p. 139-154, 2010.

VANDEVIVERE P. et. al. Types of anaerobic digesters for solid wastes inbiomethanization of the organic fraction of municipal solid wastes. IWA Publishing, v. 4, p. 111-147, London, 2002.

VENTURA, A. C.; FERNANDEZ, L.; ANDRADE, J. C. S. Tecnologias sociais: as organizações não governamentais no enfrentamento das mudanças climáticas e na promoção de desenvolvimento humano. Cadernos EBAPE.BR (FGV), v. X, p. 605, 2012. 